\title{
Presentation and survival by hormonal receptor status in metaplastic breast cancer: A propensity score-matched analysis
}

\author{
Siqin Wang ${ }^{\mathrm{a}, 1}$, Jin Hu ${ }^{\mathrm{b}, 1}$, Yanting Zhang ${ }^{\mathrm{c}}$, Jian Shen ${ }^{\mathrm{d}}$, Fang Dong ${ }^{\mathrm{b}}$, Ximeng Zhang ${ }^{\mathrm{b}}$, \\ Chong Lu ${ }^{\text {b, ** }}$, Dan Shang ${ }^{\text {a, * }}$ \\ a Department of Vascular Surgery, Union Hospital, Tongii Medical College, Huazhong University of Science and Technology, Wuhan, 430022, China \\ ${ }^{\mathrm{b}}$ Department of Breast and Thyroid Surgery, Union Hospital, Tongji Medical College, Huazhong University of Science and Technology, Wuhan, 430022, \\ China \\ ${ }^{\mathrm{c}}$ Department of Ultrasound, Union Hospital, Tongji Medical College, Huazhong University of Science and Technology, Wuhan, 430022, China \\ ${ }^{\mathrm{d}}$ Department of Pancreatic Surgery, Union Hospital, Tongii Medical College, Huazhong University of Science and Technology, Wuhan, 430022, China
}

\section{A R T I C L E I N F O}

\section{Article history:}

Received 8 September 2021

Received in revised form

9 October 2021

Accepted 11 October 2021

Available online 12 October 2021

\section{Keywords:}

Metaplastic

Breast cancer

Hormonal receptor status

Chemotherapy

Propensity score-matched

\begin{abstract}
A B S T R A C T
Background: Metaplastic breast cancer (MBC) is a rare and aggressive form of breast cancer. The effectiveness of chemotherapy (CT) for $\mathrm{MBC}$ remains controversial. The present study aimed to evaluate the efficacy of CT combined hormone receptor (HR) status on MBC patients with high risk (T1-4N2-3M0 and T4N0-1M0) by propensity-score matching (PSM).

Methods: A retrospective study was performed to analyze MBC from the SEER database. Breast cancerspecific survival (BCSS) was analyzed using the Kaplan-Meier curve. Cox proportional hazard models were used to assess BCSS. PSM was used to make 1:1 case-control matching.

Results: This study identified 3116 patients. The median follow-up time was 44 months (range, 1-321 months). About $62.5 \%$ of patients received CT. $23.0 \%$ of patients were HR-positive. Recurrence risk had a significant difference between the HR-negative and HR-positive groups. In the multivariable Cox regression model, CT had no benefit for MBC patients. HR status was not associated with a better prognosis. In subgroup analysis, the Kaplan-Meier analysis showed that HR-negative MBC with intermediate-risk benefited from CT. For HR-positive MBC, patients with intermediate and high risk also benefited from CT. After PSM, neither CT nor HR status was not related to better BCSS. Moreover, the use of CT could only improve the survival of HR-positive MBC patients with high risk.

Conclusion: PSM analysis showed that HR status was not associated with a better prognosis. CT was not a significant prognostic factor for prognosis. However, HR-positive MBC patients with high risk might benefit from CT.
\end{abstract}

(c) 2021 Published by Elsevier Ltd. This is an open access article under the CC BY-NC-ND license (http:// creativecommons.org/licenses/by-nc-nd/4.0/).

\section{Background}

Metaplastic breast cancer $(\mathrm{MBC})$ is a rare and aggressive form of breast cancer [1,2] comprising $<1 \%$ of all invasive breast cancers $[3,4]$. The World Health Organization (WHO) identified metaplastic histology as a unique pathological type in 2000 [5]. Wargotz et al. divided metaplastic cancer into five categories: carcinosarcoma,

\footnotetext{
* Corresponding author. Union Hospital, Tongji Medical College, Huazhong University of Science and Technology, 1277 Jiefang Avenue, Wuhan, Hubei Province, 430022, China.

** Corresponding author.

E-mail address: shangdanwh@163.com (D. Shang).

1 Dr. Wang and Hu contributed equally to this work.
}

matrix-producing carcinoma, spindle cell carcinoma, squamous cell carcinoma, and carcinoma with osteoclastic giant cells [6-10]. Recently, MBC had been described in two categories: carcinoma with squamous metaplasia and with heterologous components [11].

Of note, in the National Comprehensive Cancer Network (NCCN) breast cancer guidelines, management of $\mathrm{MBC}$ is still similar to invasive ductal carcinoma (IDC) [12]. However, compared with the IDC base on clinicopathological characteristics, the MBC is characterized by larger tumor size, less regional node metastasis, and higher tumor grade [13-15]. A previous study found that, compared with that of synchronous IDC, MBC patients with stage I-III disease had significantly worse 5-year breast cancer-specific survival (BCSS) [16]. Published studies reported that MBC was 
chemorefractory, whatever patients received either neoadjuvant or adjuvant settings [2,17-19].

Although commonly molecular subtype is the triple-negative phenotype in $\mathrm{MBC}$, hormone receptor (HR) positive and human epidermal growth receptor 2 (HER2) positive tumors do exist [20]. A population-based study suggested, HR status was not associated with better survival in MBC, which was different from IDC and lobular carcinomas [21]. In addition, antiestrogen therapy could not increase the prognosis of HR-positive MBC patients [18,19,22].

Although previous studies had reported the chemotherapy (CT) and HR status were not associated with better survival in MBC, the role of CT is still unclear for MBC with different risks of recurrence, especially when considering HR status. The purpose of our study is to evaluate the response of $\mathrm{MBC}$ to $\mathrm{CT}$ at different risks of recurrence using the database of the whole population.

\section{Materials and methods}

\subsection{SEER database and patients}

Malignant tumors are recorded by diagnosis codes according to the third edition of the International Classification of Diseases for Oncology (ICD-O-3) in the SEER database. It was comprised of open access data from 18 population-based cancer registries in the United States. Patients diagnosed with MBC were confirmed by pathology from 1975 to 2016. In our study, the ICD-O-3 codes included 8560, 8562, 8570-8572, 8575, and 8980-8982. The inclusion criteria were as follows: female, age of at least 18 years, breast cancer as first and the only cancer diagnosis, unilateral breast cancer, diagnosis obtained from histology or cytology confirmation and not from autopsy or death, complete information of known survival time and molecular subtype, stage exception of T0 and Tis and pathological stage I to III tumors (Fig. 1).

The low-risk group included patients with T1-2NOM0, the intermediate-risk group included patients with stage T1-2N1M0 and T3NOMO [23], and the high-risk group included patients with stage T1-4N2-3M0 and T4N0-1M0 [24].

\subsection{Demographic and clinicopathologic features}

The demographic parameters included age at diagnosis, race recorded by SEER (white, black, Asian or Pacific Islander, unknown). The clinicopathologic parameters included tumor grade, histologic subtype, tumor size (T1, T2, T3, and T4), regional lymph node status (N0, N1, N2, and N3), risk stratification (low risk, intermediate risk, high risk), HR status, CT, radiotherapy (RT), local therapies (lumpectomy, mastectomy, and none), and years at diagnosis. The molecular subtype was analyzed as a binary categorical variable: HRnegative (ER- and PR-) group and HR-positive (ER-/PR+, ER+/PR-, $\mathrm{ER}+/ \mathrm{PR}+$ ) group. The primary clinical outcome for this series was BCSS from the date of diagnosis to the date of death caused by MBC.

\subsection{Statistical analysis}

The Student t-test and $\chi 2$ test were performed to compare the clinicopathological characteristics between the two groups. The BCSS rates were calculated using the Kaplan-Meier model and comparisons were conducted using the log-rank test. The multivariable Cox proportional hazards regression model was performed to assess the risk factors for BCSS. Hazard ratios (HRs) were showed with $95 \%$ confidence interval (CI). All statistical analyses used SPSS statistical software (version 24.0; IBM Corporation, Armonk, NY, USA), and $\mathrm{P}<0.05$ was statistically significant.

Because of the retrospective design, a selection bias existed in the allocation of patients into the HR-negative and HR-positive groups. We compared the clinicopathologic data of the HRnegative and HR-positive groups and found that the two groups were comparable in terms of race, tumor grade, histology, tumor size, regional lymph node status, risk stratification. Therefore, we used propensity score-matching (PSM) to reduce the confounding factors and treatment selection bias [25]. Stratification by the T stage was performed to PSM. PSM was used to make 1:1 case-

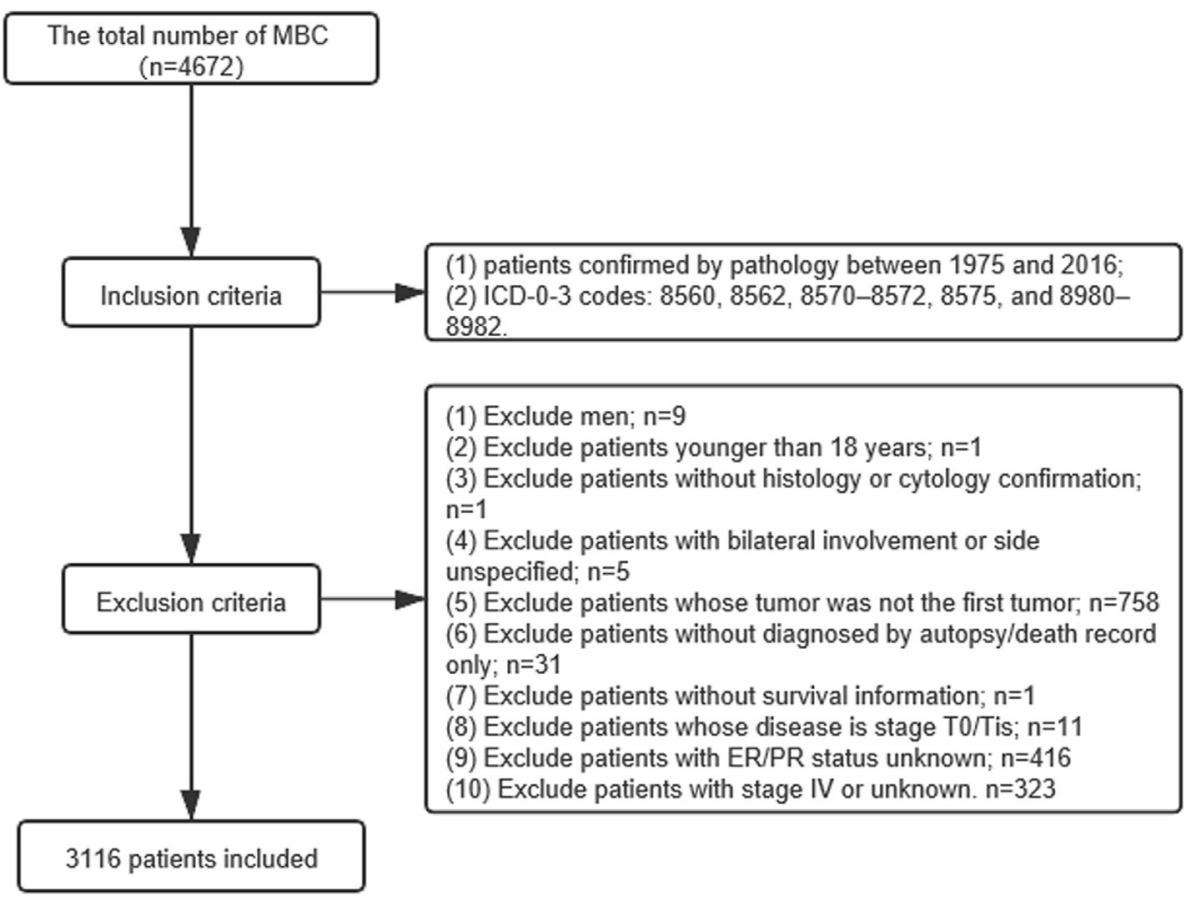

Fig. 1. Stepwise inclusion and exclusion count. 
control matching. Patients with stage T1 were included to model I with match tolerance 0.001 , stage T2 to model II with match tolerance 0.001 , stage T3 to model III with match tolerance 0.001 , and stage T4 to model IV with match tolerance 0.005 . A total of 384 (30.1\%), 644 (50.6\%), 144 (11.3\%), and 102 (8.0\%) of the patients were included in models I, II, III, and IV, respectively. The difference of the short-term clinical outcomes in the Kaplan-Meier model was conducted using the Gehan-Breslow-Wilcoxon test, while the difference of the long-term outcomes using the Log-rank test.

\section{Result}

\subsection{Demographic and clinical characteristics}

Of the $4672 \mathrm{MBC}$ patients in the SEER registry, our final sample comprised 3116 patients. The demographic and clinical characteristics in the study are shown in Table $1.23 .0 \%$ (716/3116) of patients were HR-positive. About $62.5 \%$ (1948/3116) of patients received CT, which seems not to be based on HR status $(P=0.398)$. The median age at diagnosis was 61 (range, 22-90 years), and 62 (range, 24-90 years) in the HR-negative group and the HR-positive group, respectively. A total of 757 (24.3\%), 1861 (59.7\%), and 498 (16.0\%) patients had low-risk, intermediate-risk, and high-risk disease, respectively. Recurrence risk had a significant difference between the two groups. The HR-positive group tended to lower tumor grade, smaller tumor size, and less lymph node metastasis. The number of patients has increased every year. (Fig. S2) According to joinpoint regression, lines were fitted rates. Joinpoint occurring in 1984 (95\% confidence interval [CI], 1982 to 1986) and 2003 (95\% CI, 2002 to 2004) provided the optimal fit to the data, reflecting the years at which MBC average annual incidence rates shifted most markedly during the approximately 40 years studied (1975 to 1984 vs. 1984 to 2003 vs. 2003 to 2016). Incidence of MBC decreased before 2003 , with the decrease accelerating from $0.31 \%(95 \% \mathrm{CI}$, -0.7 to 0.1 ) per year during 1975 to 1984 to $2.73 \%(95 \% \mathrm{CI},-2.9$ to -2.6 ) per year during 1984 to 2003. In contrast, between 2003 and 2016, incidence rates increased with the increase accelerating $1.99 \%$ ( $95 \%$ CI, 1.7 to 2.2 ) per year. (Fig. S3).

Table 1

Demographic and clinical characteristics in MBC patients.

\begin{tabular}{|c|c|c|c|c|c|c|}
\hline \multirow[t]{2}{*}{ Characteristic } & \multicolumn{3}{|l|}{ Before PSM } & \multirow{2}{*}{$\overline{\text { HR-negative }}$} & \multicolumn{2}{|l|}{ After PSM } \\
\hline & HR-negative & HR-positive & $\mathrm{p}$ & & HR-positive & $\mathrm{p}$ \\
\hline & $\mathrm{n}=2400$ & $\mathrm{n}=716$ & & $\mathrm{n}=637$ & $\mathrm{n}=637$ & \\
\hline Age (median) & $61(22-90)$ & $62(24-90)$ & 0.761 & $62(22-90)$ & $62(22-90)$ & 0.875 \\
\hline Follow-up time (median) & $47(1-320)$ & $40(1-321)$ & 0.003 & $44(1-280)$ & $41(1-321)$ & 0.632 \\
\hline Race & & & 0.023 & & & 0.850 \\
\hline White & $1859(77.5)$ & $534(74.6)$ & & $488(76.6)$ & $501(78.6)$ & \\
\hline Black & $372(15.5)$ & $109(15.2)$ & & $97(15.2)$ & $89(14.0)$ & \\
\hline Asian or Pacific Islander & $151(6.3)$ & $61(8.5)$ & & $47(7.4)$ & $42(6.6)$ & \\
\hline Other & $18(0.8)$ & $12(1.7)$ & & $5(0.8)$ & $5(0.8)$ & \\
\hline Grade & & & 0.005 & & & 0.981 \\
\hline Well differentiated & $88(3.7)$ & $33(4.6)$ & & $27(4.2)$ & $28(4.4)$ & \\
\hline Moderately differentiated & $253(10.5)$ & $105(14.7)$ & & $83(13.0)$ & $89(14.0)$ & \\
\hline Poorly differentiated & $1625(67.7)$ & $477(66.6)$ & & $442(69.4)$ & $433(68.0)$ & \\
\hline Undifferentiated & $117(4.9)$ & $24(3.4)$ & & $19(3.0)$ & $21(3.3)$ & \\
\hline Unknown & $317(13.2)$ & $77(10.8)$ & & $66(10.4)$ & $66(10.4)$ & \\
\hline Histology & & & 0.005 & & & 0.561 \\
\hline Metaplastic carcinoma & $1920(80.0)$ & $564(78.8)$ & & $536(84.1)$ & $520(81.6)$ & \\
\hline Carcinosarcoma & $120(5.0)$ & $20(2.8)$ & & $17(2.7)$ & $13(2.0)$ & \\
\hline Adenosquamous carcinoma & $122(5.1)$ & $55(7.7)$ & & $38(6.0)$ & $45(7.1)$ & \\
\hline Adenocarcinoma with squamous metaplasia & $97(4.0)$ & $38(5.3)$ & & $20(3.1)$ & $26(4.1)$ & \\
\hline Others & $141(5.9)$ & $39(5.4)$ & & $26(4.1)$ & $33(5.2)$ & \\
\hline Tumor size & & & 0.023 & & & 1.000 \\
\hline $\mathrm{T} 1$ & $636(26.5)$ & $216(30.2)$ & & $192(30.1)$ & $192(30.1)$ & \\
\hline $\mathrm{T} 2$ & $1206(50.2)$ & $347(48.5)$ & & $322(50.5)$ & $322(50.5)$ & \\
\hline T3 & $390(16.3)$ & $93(13.0)$ & & $72(11.3)$ & $72(11.3)$ & \\
\hline $\mathrm{T} 4$ & $168(7.0)$ & $59(8.2)$ & & $51(8.0)$ & $51(8.0)$ & \\
\hline Regional lymph node status & & & 0.005 & & & 0.180 \\
\hline NO & 1893 (78.9) & $526(73.5)$ & & $463(72.7)$ & $493(77.4)$ & \\
\hline N1 & $382(15.9)$ & $128(17.9)$ & & $131(20.6)$ & $105(16.5)$ & \\
\hline $\mathrm{N} 2$ & $78(1.6)$ & $36(5.0)$ & & $22(3.5)$ & $24(3.8)$ & \\
\hline N3 & $47(2.0)$ & $26(3.7)$ & & $21(3.3)$ & $15(2.4)$ & \\
\hline Risk stratification & & & 0.024 & & & 0.865 \\
\hline Low risk & $569(23.7)$ & $188(26.3)$ & & 165 (25.9) & $173(27.2)$ & \\
\hline Intermediate risk & $1464(61.0)$ & $397(55.4)$ & & $370(58.1)$ & $366(57.5)$ & \\
\hline High risk & $367(15.3)$ & $131(18.3)$ & & $102(16.0)$ & $98(15.4)$ & \\
\hline Chemotherapy & & & 0.398 & & & 0.909 \\
\hline No & $890(37.1)$ & $278(38.8)$ & & 389 (61.1) & $387(60.8)$ & \\
\hline Yes & $1510(62.9)$ & $438(61.2)$ & & $248(38.9)$ & $250(39.2)$ & \\
\hline Radiotherapy & & & 0.149 & & & 0.955 \\
\hline No & $1307(54.5)$ & $368(51.4)$ & & 337 (52.9) & $338(53.1)$ & \\
\hline Yes & $1093(45.5)$ & $348(48.6)$ & & $300(47.1)$ & 299 (46.9) & \\
\hline Surgery type & & & 0.724 & & & 0.279 \\
\hline Lumpectomy & $1010(42.1)$ & 307 (42.9) & & $261(41.0)$ & $284(42.8)$ & \\
\hline Mastectomy & $1244(51.8)$ & $371(51.8)$ & & $340(53.4)$ & $326(51.2)$ & \\
\hline None & $146(6.1)$ & $38(5.3)$ & & $36(5.7)$ & $27(4.2)$ & \\
\hline
\end{tabular}

Abbreviations: $\mathrm{MBC}=$ metaplastic breast cancer; $\mathrm{HR}=$ Hormonal receptor; $\mathrm{PSM}=$ propensity-score matching. 


\subsection{Survival analyses before PSM}

The median follow-up time was 47 months (range, 1-320 months) in the HR-negative group and 40 months (range, 1-321 months) in the HR-positive group. BCSS at 5 years was $77.3 \%$ in patients receiving $\mathrm{CT}$ versus $75.3 \%$ in that without receiving CT $(\mathrm{P}=0.411$, Fig. 2a). In the intermediate-risk group, patients receiving CT demonstrated superior BCSS to patients without receiving CT $(82.1 \%$ at 5 years vs. $72.2 \%$ at 5 years, $\mathrm{P}<0.001$, Fig. 2c), but not saw in low-risk or high-risk groups (Fig. 2b and d).

In Cox multivariate analysis model, the risk of recurrence was significantly associated with worse BCSS (low-risk as reference, intermediate-risk: HRs 1.630; $95 \% \mathrm{CI}, 1.130-2.350 ; \mathrm{P}=0.009$; highrisk: HRs 2.847; 95 \% CI, 1.870-4.334; $\mathrm{P}<0.001$ ). Of note, HRpositive patients had no better BCSS (HRs 1.017; $95 \% \mathrm{CI}$, 0.841-1.231; $\mathrm{P}=0.860$ ) than HR-negative patients. Moreover, patients could not benefit from CT (HRs 1.104; 95 \% CI, 0.906-1.346; $\mathrm{P}=0.326$ ). In addition, race, tumor grade, and tumor histology were not related to better BCSS. However, age, RT, and surgery type were independent indicators for BCSS (Table 2).

\subsection{Survival analysis after PSM}

To analyze the independent prognostic factors for the BCSS, the Cox proportional hazards model was used. Of note, neither HR status (HR-negative as reference, HRs 1.070; 95 \% CI, 0.829-1.380; $\mathrm{P}=0.604$ ) nor CT (receiving CT as reference, HRs $0.893 ; 95 \% \mathrm{CI}$, 0.644-1.237; $\mathrm{P}=0.495$ ) was associated with outcome. The parameters with significant difference related to a better prognosis of MBC were age (HRs 1.025; 95 \% CI, 1.015-1.036; P < 0.001), risk stratification (low-risk as reference, intermediate risk, HRs 2.747; 95 \% CI, 1656-4.556; P > 0.001; high-risk, HRs 9.587; 95 \% CI,
5.597-16.423; $\mathrm{P}<0.001$ ), and surgery types (lupectomy as reference, mastectomy, HRs 1.647; $95 \% \mathrm{CI}, 1.160-2.338$; $\mathrm{P}<0.005$; None, HRs 2.660; 95 \% CI, 1.484-4.768; P < 0.001). However, race, tumor grade, tumor histology, and radiotherapy were not associated with better BCSS (Table 2).

\subsection{Subtype analysis for the role of HR status in chemotherapy}

Our study further evaluated the role of CT in patients with different HR status. In Kaplan-Meier analysis, when HR status was negative, intermediate-risk patients received CT had superior survival than those not receiving $C T(P<0.001$, Fig. 3e). When HR status was positive, intermediate- and high-risk patients receiving CT had better survival than that without CT (intermediate-risk group, $\mathrm{P}=0.027$, Fig. 3f; high-risk group, $\mathrm{P}=0.010$, Fig. 3 h). For patients within a low-risk group or entire cohort, CT was not associated with better BCSS regardless of HR status (Fig. 3a-d). In the PSM data set, however, only HR-positive patients with high risk could benefit from CT ( $\mathrm{P}=0.046$, Fig. $4 \mathrm{~h})$. Of note, CT might improve the short-term clinical outcomes for patients with intermediate-risk regardless of HR status (HR-negative, the GehanBreslow-Wilcoxon test $\mathrm{P}=0.047$; HR-positive, the Gehan-BreslowWilcoxon test $\mathrm{P}=0.017$ ).

To reduce bias related to changed definitions, we extracted information of patients diagnosed from 2006 to 2016. Prognostic factors after PSM for BCSS in early and locally advanced MBC by multivariate analyses showed in supplement Table 1. Kaplan-Meier analysis showed that only HR-positive patients with high risk could benefit from CT (Supplementary Fig. 1).
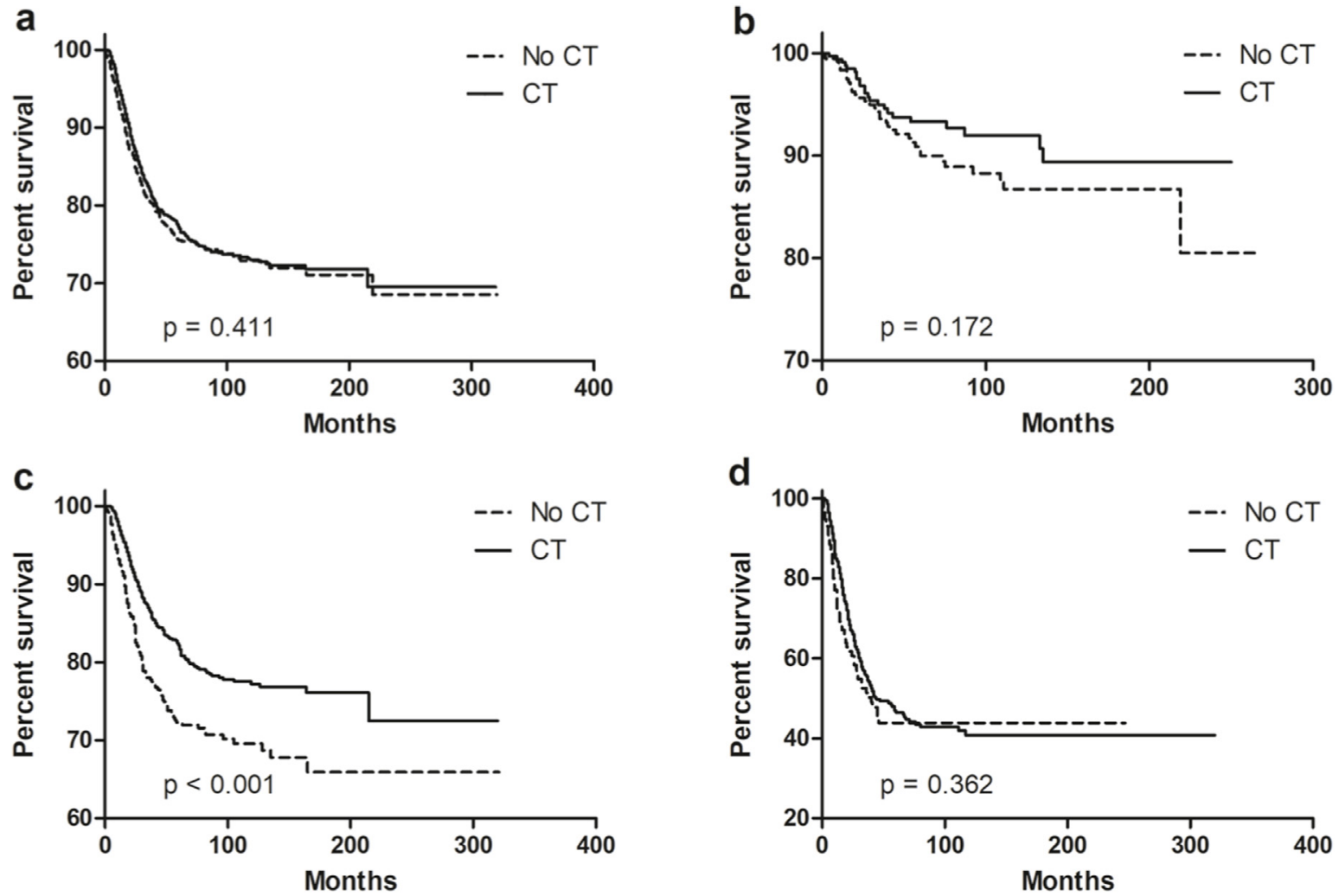

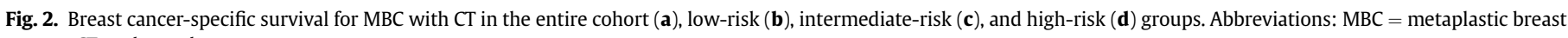
cancer; $\mathrm{CT}=$ chemotherapy. 
Table 2

Prognostic factors for BCSS in early and locally advanced MBC by multivariate analyses.

\begin{tabular}{|c|c|c|c|c|}
\hline \multirow[t]{2}{*}{ Variables } & \multicolumn{2}{|l|}{ Before PSM } & \multicolumn{2}{|l|}{ After PSM } \\
\hline & HRs (95 \% CI) & $\mathrm{p}$ & HRs (95 \% CI) & $\mathrm{p}$ \\
\hline Age & $1.014(1.007-1.020)$ & $<0.001$ & $1.025(1.015-1.036)$ & $<0.001$ \\
\hline \multicolumn{5}{|l|}{ Race } \\
\hline White & 1.0 [reference] & & 1.0 [reference] & \\
\hline Black & $1.100(0.887-1.365)$ & 0.384 & $1.180(0.824-1.690)$ & 0.366 \\
\hline Asian or Pacific Islander & $0.905(0.645-1.271)$ & 0.565 & $0.900(0.534-1.518)$ & 0.693 \\
\hline Other & $0.967(0.472-1.983)$ & 0.927 & $1.022(0.251-4.163)$ & 0.976 \\
\hline \multicolumn{5}{|l|}{ Grade } \\
\hline Well differentiated & 1.0 [reference] & & 1.0 [reference] & \\
\hline Moderately differentiated & $0.750(0.378-1.488)$ & 0.411 & $1.761(0.402-7.714)$ & 0.453 \\
\hline Poorly differentiated & $1.312(0.704-2.446)$ & 0.392 & $3.279(0.793-13.553)$ & 0.101 \\
\hline Undifferentiated & $2.039(1.033-4.024)$ & 0.040 & $4.506(0.991-20.491)$ & 0.051 \\
\hline Unknown & $1.493(0.781-2.856)$ & 0.224 & $4.266(0.993-18.323)$ & 0.051 \\
\hline \multicolumn{5}{|l|}{ Histology } \\
\hline Metaplastic carcinoma & 1.0 [reference] & & 1.0 [reference] & \\
\hline Carcinosarcoma & $1.061(0.731-1.541)$ & 0.754 & $0.861(0.367-2.018)$ & 0.731 \\
\hline Adenosquamous carcinoma & $0.846(0.558-1.283)$ & 0.432 & $1.047(0.589-1.860)$ & 0.877 \\
\hline Adenocarcinoma with squamous metaplasia & $0.992(0.694-1.418)$ & 0.965 & $1.343(0.801-2.252)$ & 0.264 \\
\hline Others & $0.812(0.559-1.180)$ & 0.275 & $0.843(0.425-1.670)$ & 0.624 \\
\hline \multicolumn{5}{|l|}{ Risk stratification } \\
\hline Low risk & 1.0 [reference] & & 1.0 [reference] & \\
\hline Intermediate risk & $1.630(1.130-2.350)$ & 0.009 & $2.747(1656-4.556)$ & $<0.001$ \\
\hline High risk & $2.847(1.870-4.334)$ & $<0.001$ & $9.587(5.597-16.423)$ & $<0.001$ \\
\hline \multicolumn{5}{|l|}{ HR status } \\
\hline $\mathrm{HR}(-)$ & 1.0 [reference] & & 1.0 [reference] & \\
\hline $\operatorname{HR}(+)$ & $1.017(0.841-1.231)$ & 0.860 & $1.070(0.829-1.380)$ & 0.604 \\
\hline \multicolumn{5}{|l|}{ Chemotherapy } \\
\hline Yes & 1.0 [reference] & & 1.0 [reference] & \\
\hline No & $1.104(0.906-1.346)$ & 0.326 & $0.893(0.644-1.237)$ & 0.495 \\
\hline \multicolumn{5}{|l|}{ Radiotherapy } \\
\hline Yes & 1.0 [reference] & & 1.0 [reference] & \\
\hline No & $1.221(1.022-1.458)$ & 0.028 & $0.836(0.623-1.120)$ & 0.23 \\
\hline \multicolumn{5}{|l|}{ Surgery types } \\
\hline Lumpectomy & 1.0 [reference] & & 1.0 [reference] & \\
\hline Mastectomy & $1.242(1.006-1.534)$ & 0.044 & $1.647(1.160-2.338)$ & 0.005 \\
\hline None & $1.403(0.970-2.030)$ & 0.072 & $2.660(1.484-4.768)$ & 0.001 \\
\hline
\end{tabular}

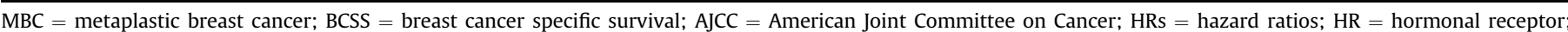
$\mathrm{PSM}=$ propensity-score matching.

\section{Discussion}

The present study examined the effect of CT on the prognosis of MBC patients and explored the role of HR in prognosis when patients under different risks of recurrence. After propensity score matching and using the variables as covariates considered importantly by some scholars $[13,26]$, our results showed that only HRpositive patients with high risk could benefit from CT. Of note, CT might improve the short-term clinical outcomes for patients with intermediate-risk regardless of HR status.

Although the previous studies showed MBC had a good survival, they had a small sample and short follow-up period [27-30]. A study reported median survival for metastatic MBC patients was less than 1 year [31]. MBC patients with stage IV have different management and survival outcomes relative to patients with stage I-III $[18,19]$. As mentioned above, this study excluded MBC patients with distant metastasis.

The proportion of $\mathrm{MBC}$ receiving CT ranged from 33 to $86 \%$ $[13,18,32]$. On the one hand, the wide proportion may indicate that the effect of CT was not yet certain in MBC patients, although several small, single-institution, and the single-arm studies showed that CT could improve the prognosis of MBC [33-35]. On the other hand, that patients received CT with a high rate may be due to that MBC's commonly molecular subtype is the triple-negative phenotype and it is characterized by larger tumor size, less regional node metastasis, and higher tumor grade [36]. There was also another reason that the management strategy of $\mathrm{MBC}$ was similar to traditional breast cancer in the NCCN guideline [12]. However, most studies had illustrated that CT might not affect the outcome of MBC $[2,14,16,17]$. In our study, $62.5 \%$ of patients underwent CT but they cannot benefit from it, which was consistent with the previous study [37,38]. However, in the subgroup analysis, only HR-positive patients with high risk could benefit from CT. That has not been appreciated so far. The reason for this effect could be the fact that our research population excluded patients with distant metastasis and follow-up was longer than published studies. Besides this, different risks of recurrence may be also worth considering.

HR positivity has been considered as a biomarker as a better outcome for traditional breast cancer. However, previously published literature illustrated HR status was not associated with the prognosis of MBC [21]. As reporting by Schroeder et al. [36], for early and locally advanced MBC patients, HER2 but not HR status was associated with superior survival. In addition, they also found that survival was parallel between HER2-positive MBC and HER2positive IDC. However, most researchers concluded that the survival of $\mathrm{MBC}$ patients was the worse carcinoma in traditional breast cancer $[14,17,39]$. Many relatively consistent observation studies showed that MBC tended negative biomarkers [ER, PR, HER2] $[14,40-42]$. Previous studies reported that about $1-17 \%$ of cases expressed HR-positivity $[7,8,43]$. In the present study, $23.0 \%$ of patients were HR-positive cases. Our results released that HR status was not associated with a better prognosis, which was consistent with the result of Wright et al. reported [21].

However, Wright et al. only conducted the Kaplan-Meier model 
a

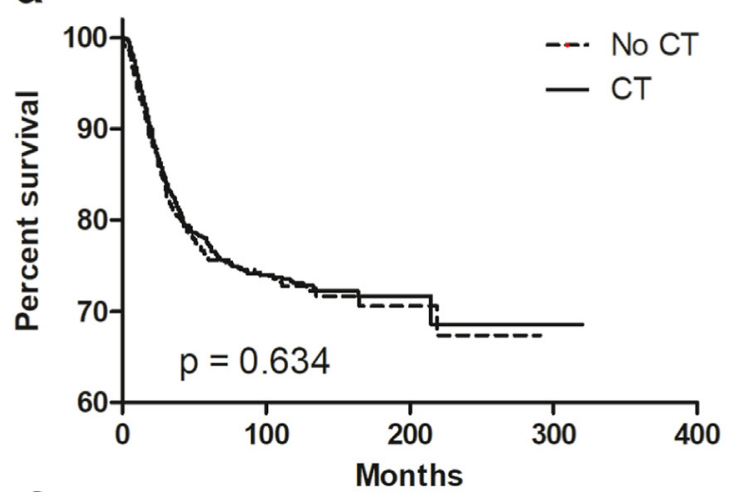

\section{C}

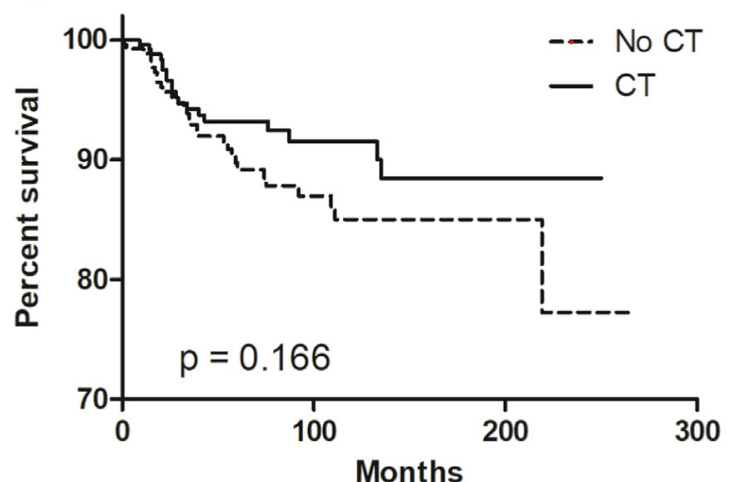

e

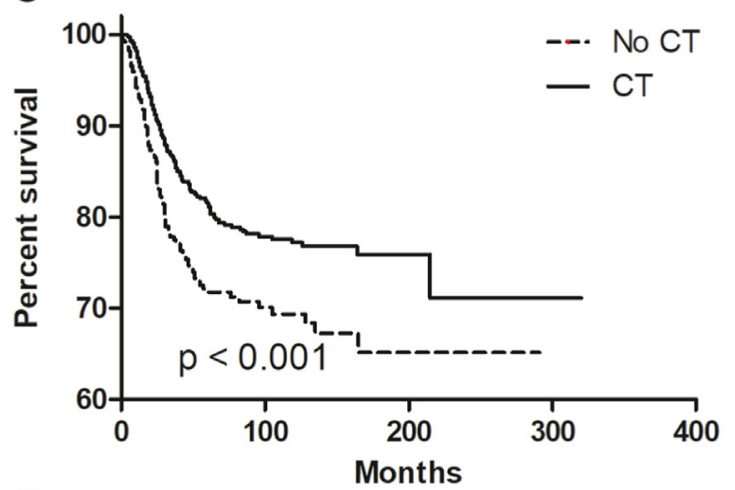

g

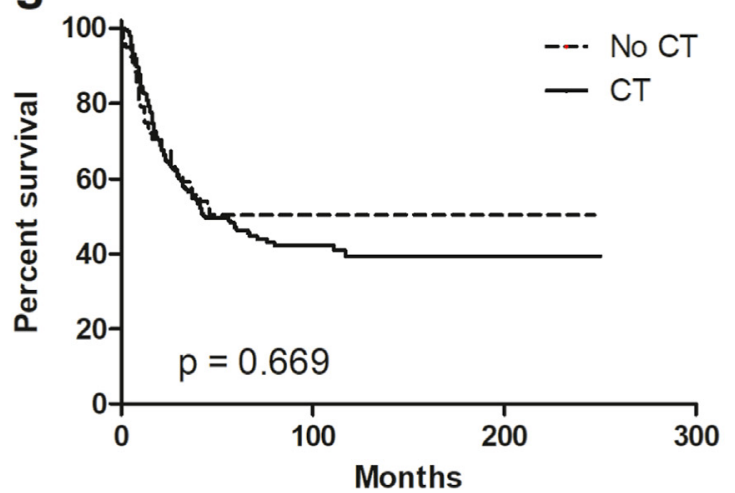

b
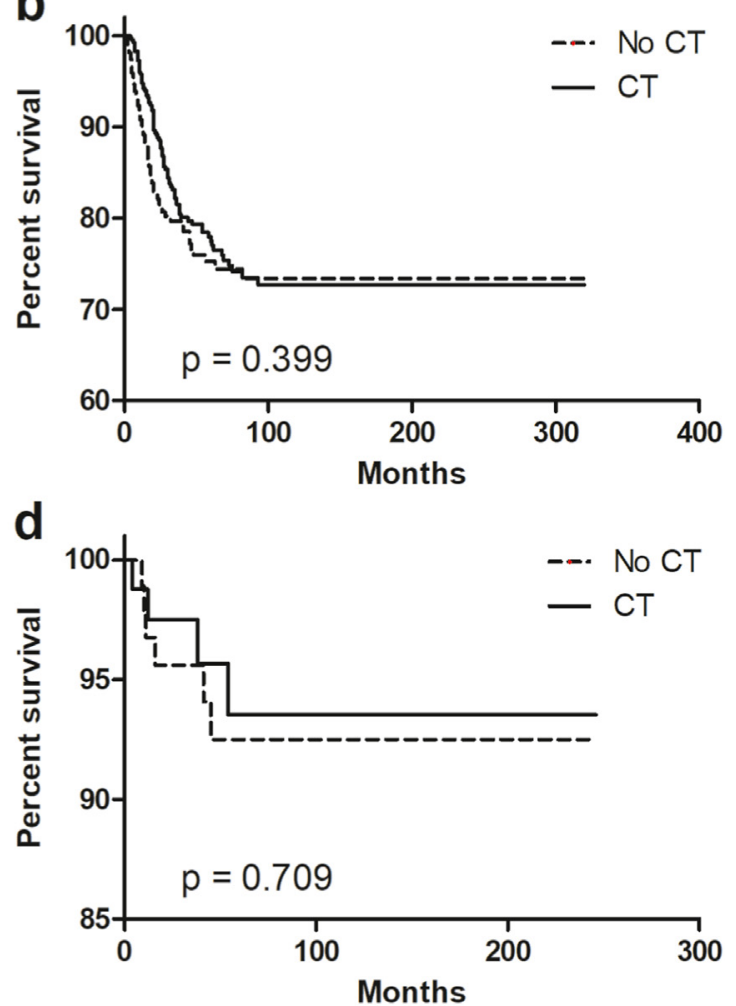

f
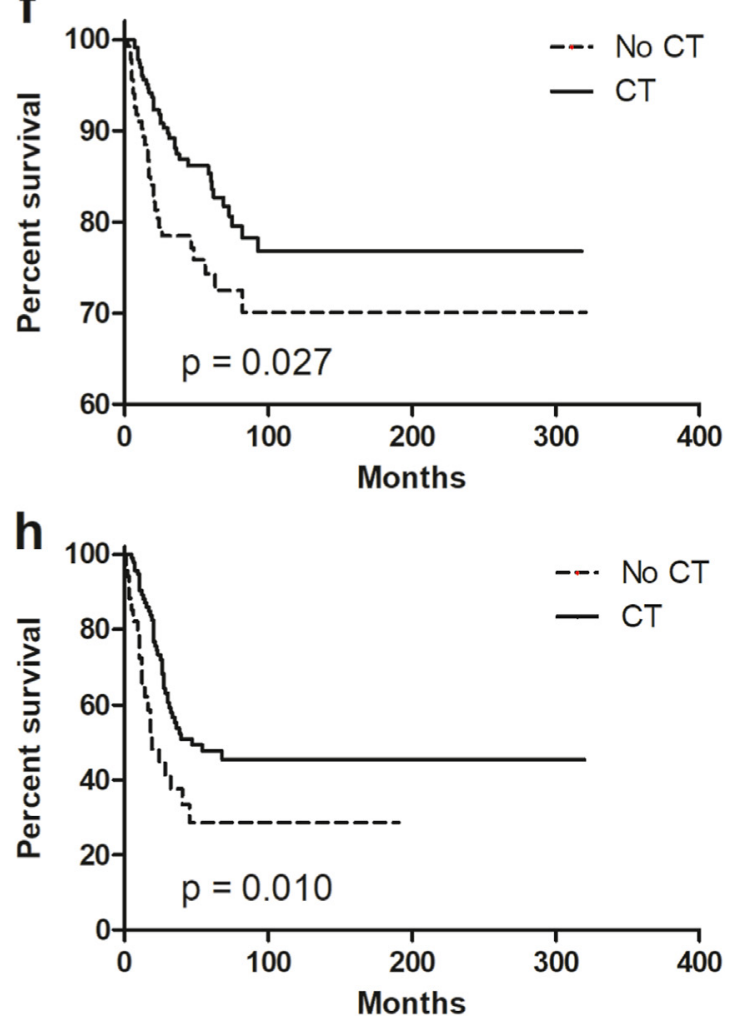

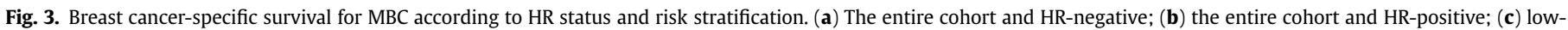

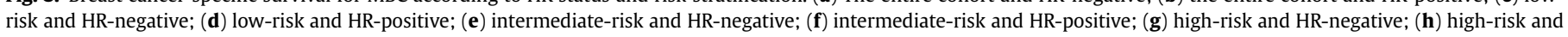
HR-positive. Abbreviations: $\mathrm{MBC}=$ metaplastic breast cancer; $\mathrm{CT}=$ chemotherapy; $\mathrm{HR}=$ hormonal receptor. 
a

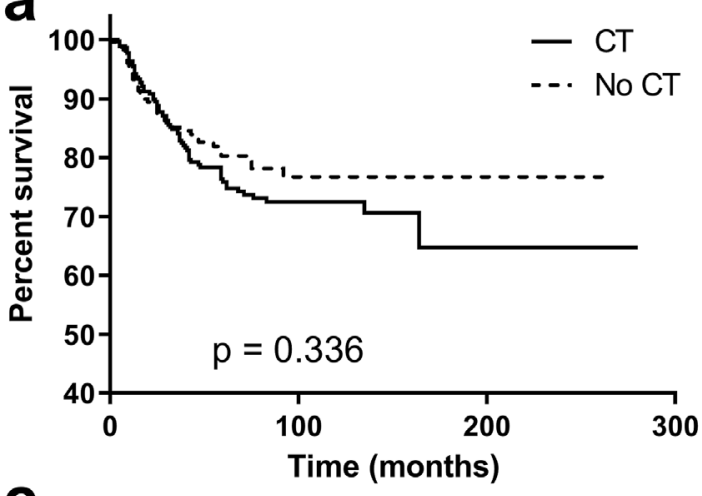

C

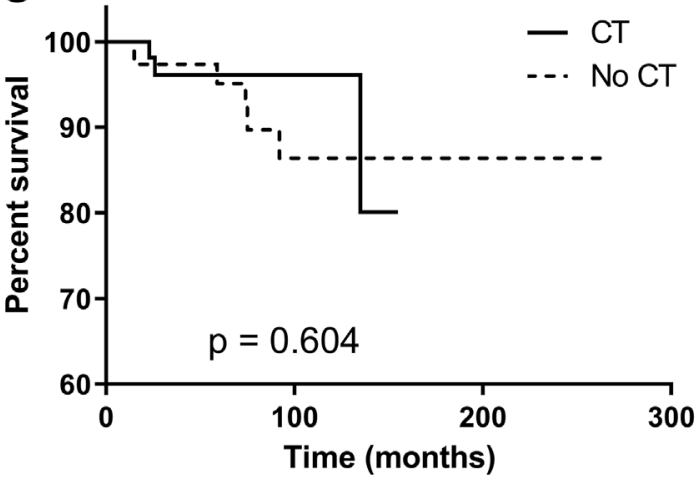

e

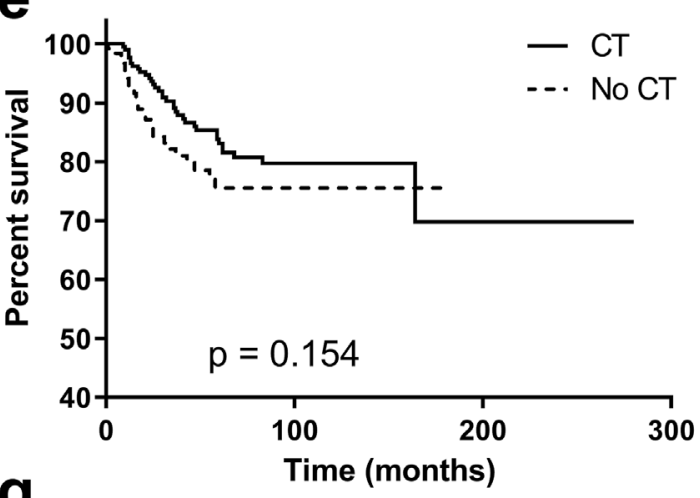

g

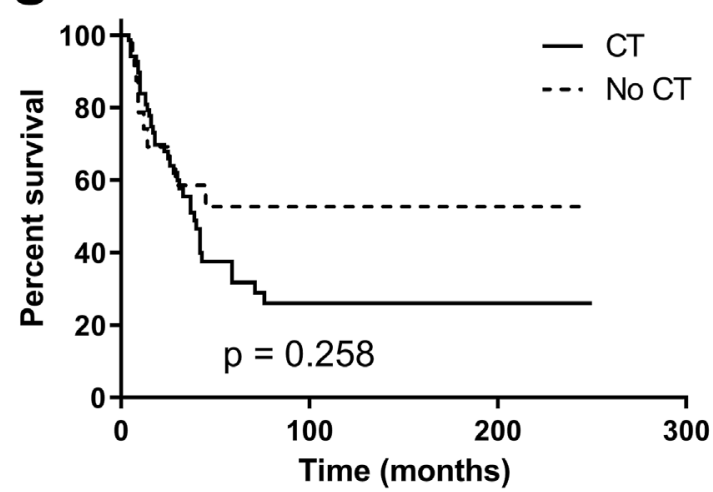

b
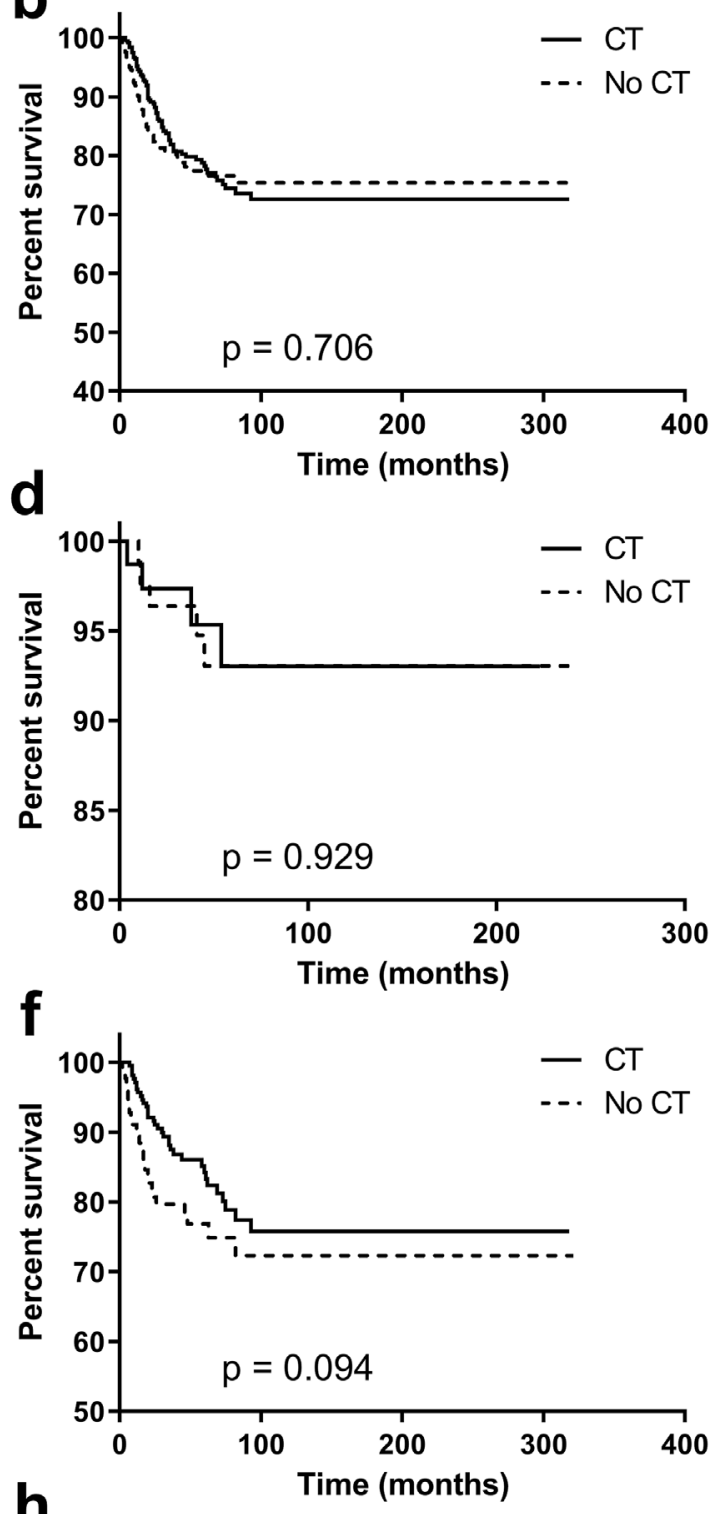

h

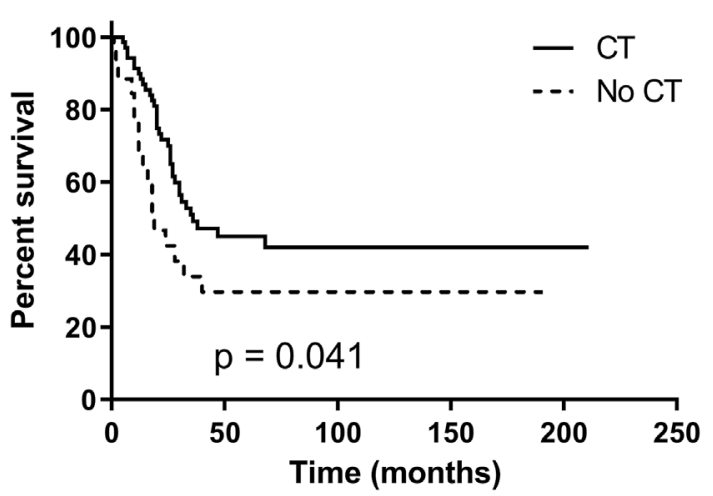

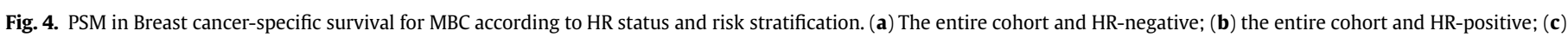

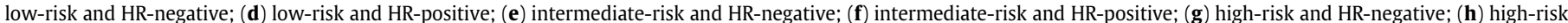
and HR-positive. Abbreviations: PSM = propensity-score matching; $\mathrm{MBC}=$ metaplastic breast cancer; $\mathrm{CT}=$ chemotherapy; $\mathrm{HR}=$ hormonal receptor. 
and log-rank test without further analysis. In our study, subtype analysis was performed to explore the response of HR status to CT according to risk stratification before and after PSM. Our research found that patients with low risk cannot benefit from CT regardless of HR status. The reason for this phenomenon could be a smaller tumor size with a low risk of hematogenous metastasis. In addition, patients with intermediate-risk might benefit from CT regardless of HR status. However, patients with high risk benefited from CT only when they expressed HR positivity. Such an occurrence probably accounts for HR-negative MBC patients with a worse prognosis than triple-negative breast cancer (TNBC) [14,17,38].

The European Society for Medical Oncology has adopted the statement that MBC patients are recommended to undergo CT from the 2013 St. Gallen consensus statement. The possible reason for this could be the fact that the HR status was commonly negative [44,45]. A clinical overview study from Abouharb et al. [31] showed that the role of targeted therapies was a major investigation. Due to different molecular phenotypes, $\mathrm{MBC}$ can particularly benefit from these management strategies, as evidenced by Adams' case report [34]. For this aggressive tumor, molecular analysis was important.

There were several limitations to our study. Firstly, it was characterized by the observational nature and the possibility of selection bias because of its retrospective study. Secondly, the SEER database lacks informations of hormone therapy and baseline characteristics of $\mathrm{MBC}$ patients, including performance status, comorbidities, and socio-economic environment parameters. Thirdly, detailed chemotherapy regimens and radiotherapy information could not be available from the SEER database, so that further case-control studies could not be performed. However, our results will help researchers to understand the role of molecular subtypes in the prognosis of MBC.

Our study has several key strengths. The involvement of CT in the prognosis of MBC is unclear. From our results, when stratified by recurrence risk, the prognosis was improved in MBC patients receiving $C T$. In addition, although studies had reported that $\mathrm{HR}$ status was not related to prognosis, HR status can redefine the role of chemotherapy in the prognosis of MBC.

\section{Conclusion}

Although HR status had no effect on the prognosis of MBC and CT was not associated with a better BCSS, HR-positive patients with high risk could benefit from CT. Of note, CT might improve the short-term clinical outcomes for patients with intermediate-risk regardless of HR status. The role of HR status is particularly important for the treatment of early and locally advanced metaplastic cancer of the breast.

\section{Declaration of competing interest}

The authors declare that they have no conflict of interest.

\section{Acknowledgment}

We sincerely appreciate our department members for providing great support.

\section{Appendix A. Supplementary data}

Supplementary data to this article can be found online at https://doi.org/10.1016/j.breast.2021.10.004.

\section{Funding}

Not applicable.

\section{Availability of data and material}

The datasets generated during and/or analyzed during the current study are available in the Figshare.com repository, https://doi. org/10.6084/m9.figshare.11985234.

\section{References}

[1] Schwartz TL, Mogal H, Papageorgiou C, Veerapong J, Hsueh EC. Metaplastic breast cancer: histologic characteristics, prognostic factors and systemic treatment strategies. Exp Hematol Oncol 2013;2:31.

[2] Tzanninis IG, Kotteas EA, Ntanasis-Stathopoulos I, Kontogianni P, Fotopoulos G. Management and outcomes in metaplastic breast cancer. Clin Breast Cancer 2016;16:437-43.

[3] Tavassoli FA. Classification of metaplastic carcinomas of the breast. Pathol Annu 1992:27 Pt 2:89-119.

[4] Rosen PP. Rosen's breast pathology. 1997.

[5] Fritz A, Percy C, Jack A, Shanmugaratnam K, Sobin L, Parkin DM, et al. International classification of diseases for oncology. 2000. Third Edition.

[6] Wargotz ES, Norris HJ. Metaplastic carcinomas of the breast. I. Matrixproducing carcinoma. Hum Pathol 1989;20:628-35.

[7] Wargotz ES, Deos PH, Norris HJ. Metaplastic carcinomas of the breast. II. Spindle cell carcinoma. Hum Pathol 1989;20:732-40.

[8] Wargotz ES, Norris HJ. Metaplastic carcinomas of the breast. III. Carcinosarcoma Cancer 1989;64:1490-9.

[9] Wargotz ES, Norris HJ. Metaplastic carcinomas of the breast. IV. Squamous cell carcinoma of ductal origin. Cancer 1990;65:272-6.

[10] Wargotz ES, Norris HJ. Metaplastic carcinomas of the breast: V. Metaplastic carcinoma with osteoclastic giant cells. Hum Pathol 1990;21:1142-50.

[11] Dave G, Cosmatos H, Do T, Lodin K, Varshney D. Metaplastic carcinoma of the breast: a retrospective review. Int J Radiat Oncol Biol Phys 2006;64:771-5.

[12] Telli ML, Gradishar WJ, Ward JH. NCCN guidelines updates: breast cancer. J Natl Compr Cancer Netw 2019;17:552-5.

[13] Pezzi CM, Patel-Parekh L, Cole K, Franko J, Klimberg VS, Bland K. Characteristics and treatment of metaplastic breast cancer: analysis of 892 cases from the National Cancer Data Base. Ann Surg Oncol 2007;14:166-73.

[14] Jung SY, Kim HY, Nam BH, Min SY, Lee SJ, Park C, et al. Worse prognosis of metaplastic breast cancer patients than other patients with triple-negative breast cancer. Breast Cancer Res Treat 2010;120:627-37.

[15] Lim KH, Oh DY, Chie EK, Han W, Im SA, Kim TY, et al. Metaplastic breast carcinoma: clinicopathologic features and prognostic value of triple negativity. Jpn J Clin Oncol 2010;40:112-8.

[16] Nelson RA, Guye ML, Luu T, Lai LL. Survival outcomes of metaplastic breast cancer patients: results from a US population-based analysis. Ann Surg Oncol 2015;22:24-31.

[17] Bae SY, Lee SK, Koo MY, Hur SM, Choi MY, Cho DH, et al. The prognoses of metaplastic breast cancer patients compared to those of triple-negative breast cancer patients. Breast Cancer Res Treat 2011;126:471-8.

[18] Hennessy BT, Giordano S, Broglio K, Duan Z, Trent J, Buchholz TA, et al. Biphasic metaplastic sarcomatoid carcinoma of the breast. Ann Oncol 2006;17:605-13.

[19] Lee H, Jung SY, Ro JY, Kwon Y, Sohn JH, Park IH, et al. Metaplastic breast cancer: clinicopathological features and its prognosis. J Clin Pathol 2012;65: $441-6$.

[20] Edenfield J, Schammel C, Collins J, Schammel D, Edenfield WJ. Metaplastic breast cancer: molecular typing and identification of potential targeted therapies at a single institution. Clin Breast Cancer 2017;17:e1-10.

[21] Paul Wright G, Davis AT, Koehler TJ, Melnik MK, Chung MH. Hormone receptor status does not affect prognosis in metaplastic breast cancer: a population-based analysis with comparison to infiltrating ductal and lobular carcinomas. Ann Surg Oncol 2014;21:3497-503.

[22] Song Y, Liu X, Zhang G, Song H, Ren Y, He X, et al. Unique clinicopathological features of metaplastic breast carcinoma compared with invasive ductal carcinoma and poor prognostic indicators. World J Surg Oncol 2013;11:129.

[23] Velikova G, Williams LJ, Willis S, Dixon JM, Loncaster J, Hatton M, et al. Quality of life after postmastectomy radiotherapy in patients with intermediate-risk breast cancer (SUPREMO): 2-year follow-up results of a randomised controlled trial. Lancet Oncol 2018;19:1516-29.

[24] Wang SL, Fang H, Song YW, Wang WH, Hu C, Liu YP, et al. Hypofractionated versus conventional fractionated postmastectomy radiotherapy for patients with high-risk breast cancer: a randomised, non-inferiority, open-label, phase 3 trial. Lancet Oncol 2019;20:352-60.

[25] Austin PC. An introduction to propensity score methods for reducing the effects of confounding in observational studies. Multivariate Behav Res 2011;46:399-424.

[26] Wang J, Zhang WW, Lian CL, Sun JY, He ZY, Wu SG. The effect of postmastectomy radiotherapy in patients with metaplastic breast cancer: an analysis of SEER database. Front Oncol 2019;9:747.

[27] Chao TC, Wang CS, Chen SC, Chen MF. Metaplastic carcinomas of the breast. J Surg Oncol 1999;71:220-5.

[28] Denley H, Pinder SE, Tan PH, Sim CS, Brown R, Barker T, et al. Metaplastic carcinoma of the breast arising within complex sclerosing lesion: a report of 
five cases. Histopathology 2000;36:203-9.

[29] Rosen PP, Ernsberger D. Low-grade adenosquamous carcinoma. A variant of metaplastic mammary carcinoma. Am J Surg Pathol 1987;11:351-8.

[30] Suster S, Moran CA, Hurt MA. Syringomatous squamous tumors of the breast. Cancer 1991;67:2350-5.

[31] Abouharb S, Moulder S. Metaplastic breast cancer: clinical overview and molecular aberrations for potential targeted therapy. Curr Oncol Rep 2015;17: 431.

[32] Rayson D, Adjei AA, Suman VJ, Wold LE, Ingle JN. Metaplastic breast cancer: prognosis and response to systemic therapy. Ann Oncol 1999;10:413-9.

[33] Swathy PU, Arunalatha P, Chandramouleeswari K, Lily SM, Ramya S. Adenosquamous variant of metaplastic carcinoma of breast - an unusual histological variant. J Clin Diagn Res 2015;9. Ed05-6.

[34] Adams S. Dramatic response of metaplastic breast cancer to chemo-immunotherapy. NPJ Breast Cancer 2017;3:8

[35] Hamad L, Khoury T, Vona K, Nestico J, Opyrchal M, Salerno KE. A case of metaplastic breast cancer with prolonged response to single agent Liposomal Doxorubicin. Cureus 2016;8:e454.

[36] Schroeder MC, Rastogi P, Geyer Jr CE, Miller LD, Thomas A. Early and locally advanced metaplastic breast cancer: presentation and survival by receptor status in surveillance, epidemiology, and end results (SEER) 2010-2014. Oncol 2018;23:481-8.

[37] Ong CT, Campbell BM, Thomas SM, Greenup RA, Plichta JK, Rosenberger LH, et al. Metaplastic breast cancer treatment and outcomes in 2500 patients: a retrospective analysis of a national Oncology database. Ann Surg Oncol 2018;25:2249-60.
[38] Polamraju P, Haque W, Cao K, Verma V, Schwartz M, Klimberg VS, et al. Comparison of outcomes between metaplastic and triple-negative breast cancer patients. Breast 2020;49:8-16.

[39] He X, Ji J, Dong R, Liu H, Dai X, Wang C, et al. Prognosis in different subtypes of metaplastic breast cancer: a population-based analysis. Breast Cancer Res Treat 2019;173:329-41.

[40] Lai HW, Tseng LM, Chang TW, Kuo YL, Hsieh CM, Chen ST, et al. The prognostic significance of metaplastic carcinoma of the breast (MCB)-a case controlled comparison study with infiltrating ductal carcinoma. Breast 2013;22:968-73.

[41] Reis-Filho JS, Milanezi F, Carvalho S, Simpson PT, Steele D, Savage K, et al. Metaplastic breast carcinomas exhibit EGFR, but not HER2, gene amplification and overexpression: immunohistochemical and chromogenic in situ hybridization analysis. Breast Cancer Res 2005;7:R1028-35.

[42] Leibl S, Moinfar F. Metaplastic breast carcinomas are negative for Her-2 but frequently express EGFR (Her-1): potential relevance to adjuvant treatment with EGFR tyrosine kinase inhibitors? J Clin Pathol 2005;58:700-4.

[43] Gutman H, Pollock RE, Janjan NA, Johnston DA. Biologic distinctions and therapeutic implications of sarcomatoid metaplasia of epithelial carcinoma of the breast. J Am Coll Surg 1995;180:193-9.

[44] Goldhirsch A, Winer EP, Coates AS, Gelber RD, Piccart-Gebhart M, Thurlimann B, et al. Personalizing the treatment of women with early breast cancer: highlights of the St Gallen international expert consensus on the primary therapy of early breast cancer 2013. Ann Oncol 2013;24:2206-23.

[45] Senkus E, Kyriakides S, Penault-Llorca F, Poortmans P, Thompson A, Zackrisson S, et al. Primary breast cancer: ESMO Clinical Practice Guidelines for diagnosis, treatment and follow-up. Ann Oncol 2013;24(Suppl 6). vi7-23. 